\title{
Analysis on Technological Innovation of Civil Engineering Construction
}

\author{
Lili Hu \\ China West Normal University, Nanchong, China \\ Email: guicaitang@163.com
}

Received 13 April 2016; accepted 14 May 2016; published 17 May 2016

Copyright (C) 2016 by author and Scientific Research Publishing Inc.

This work is licensed under the Creative Commons Attribution International License (CC BY). http://creativecommons.org/licenses/by/4.0/

c) (i) Open Access

\begin{abstract}
As an important means of human to change their living environment, building creates important wellbeing for people's production and life, while as an important means of building construction, civil engineering plays an absolutely important role in the architectural construction. The fruitful innovation in the construction of civil engineering undoubtedly has a very important meaning and value for the development of civil engineering discipline and for the realization of human wellbeing. This paper makes analysis on several means of technological innovation of civil engineering construction, purposed to promote the practical development of civil engineering through helpful discussion and exploration.
\end{abstract}

\section{Keywords}

Civil Engineering, Construction Technology, Innovative Analysis

\section{Introduction}

The technological innovation of civil engineering construction is involved with the benefit achievements and the brand creation of engineering construction companies, and also closely related with the improvement of people's living conditions. As civil engineering is the principal part of engineering construction, the construction parties of civil engineering must make technological innovation based on the changing and developing society, and use new technologies and new methods to make construction of projects. This paper makes analysis on several means of technological innovation of civil engineering construction, purposed to promote the practical development of civil engineering through helpful discussion and exploration. 


\section{Discriminate Some Concepts in Analysis of Technological Innovation of Civil Engineering Construction}

\subsection{Civil Engineering and Its Construction}

The so-called civil engineering refers to a general term of science and technology used in the construction of various types of engineering facilities, and it includes a number of disciplines and covers exploration, design, maintenance, repair and other technical activities. The final service objects of civil engineering construction is the building, while the building serves the production and life of people, so the final service object of civil engineering is people, by which civil engineering should have the characteristics of facilitating people's production and life and providing service for people. People's production and life is based on the constantly changing and developing society, so people must make innovation in the construction of civil engineering according to the social development and change, so as to meet the growing demands of people for materials and culture and to help people get a better material life and spiritual enjoyment [1].

In substance, the social development is to let more people enjoy the facilities brought by social production development, where the "people" refers to the ultimate users of engineering construction who are the ultimate beneficiaries of civil engineering construction, and the "people" should also include the persons who participate in the construction, so we should focus on the harmony and security of people in the whole process of civil engineering construction and should pay attention to the common appeal of these two groups of people during the technological innovation of construction. In the construction of civil engineering, technology is primary. The construction of civil engineering needs manpower to undertake the work related to the design and practical operation. The design and service object of civil engineering is human beings, therefore in the course of civil engineering construction, we must concern about the convenience for the workers in the construction. We should not only make the construction meet the demand of customers to the maximum extent, but also consider the workers' health and convenience in the construction, trying to avoid security risks and incidents in the construction.

\subsection{Technological Innovation of the Construction}

After all, the construction of civil engineering is a reconstruction process of the nature, so it is a problem urgently to be faced whether we can achieve a harmonious relationship between people and the nature in the construction. The technological innovation of construction is a necessary stage in the development and improvement of civil engineering. In fact, the technological innovation of construction is the best means to achieve the initial intention of civil engineering construction [2]. The construction of civil engineering is carried out according to people's demand and the technological innovation of construction can help the builders reduce the pressure from many aspects and protect their personal safety during the construction, while we can meet customers' requirements at the maximum. In the construction of civil engineering, we constantly use new technologies and techniques to save resources and implement environmentally-friendly construction, which is very significant for the long-term development of projects and the sustainable development of human society. The significance of technological innovation of the construction is also reflected in shortening construction period and saving labor cost. After new technologies are applied, the construction period is greatly shortened and the labor cost is greatly reduced based on the construction quality guaranteed and improved. It should be appreciated that application of new technologies not only represents a decrease of labor quantity and labor costs, but also means a great relief of labor intensity, so it seems that application of new technologies in the construction of civil engineering benefits the harmonious development of society.

\section{Several Problems Currently Existing in the Process of Civil Engineering Construction}

\subsection{Relatively Laggard Pit Support Technology}

Before and even at the beginning of reform and opening up, China's civil engineering is mainly purposed to build single and multi-storey residential houses. At that time, there is no demand for pit support technology. Therefore, there is no market for carrying out pit support technology at the time. Under the prevailing conditions of that time, this technology is still in its infancy and is little applied in China even though it has been widely used some big cities such as New York. 
With the continued reform and opening up and the construction of China's urbanization, China's urban residential land is currently facing increasingly tense situation, among which some big cities in China, such as Beijing and Shanghai have their land price risen increasingly, and the conventional multi-storey building no longer meet the demand of the current real estate market, while the high-rise buildings more than 30 floors have become the mainstream of current housing construction in the building market. In this case, pit support technology has become one of the necessary technologies in the construction of civil engineering in China. According to the current situation, due to the lack of historic technology accumulation in China, the development of pit support technology is not mature [3]. Although the pit support technology has been able to help the construction companies in China construct tall building foundation, but due to little accumulation of this technology in historic development, we find the difficulties are far exceeded our ability at many times when we face the complex geological structure and deal with relatively complex architectural design. For many complex real problems, there is no mature solution, so that currently the design mistakes of high-rise building occur frequently in China.

\subsection{Lack of Environmental Philosophy}

In the past, there were dust, noise, garbage, solid waste and other problems in the construction of civil engineering, which disturbed the normal production and life of the surrounding masses and affect the health of the workers at site. Now all sectors are increasingly emphasizing these environmental issues in China, so the lack of environmental philosophy will make the construction parties have a high operating cost and a high administrative cost, and it is not conducive to the brand building for the construction parties.

The lack of environmental philosophy is also reflected by no pre-planning in the construction. In fact, the current civil engineering construction is purposed not only to meet the residential need of people but also to emphasize the harmonious development between human and nature and between human and society, that is, people pursue a satisfactory and harmonious life when they have their residential buildings, while house is just a part of the environment, so we should create a whole livable environment for human through building construction. For these, we should have a rational planning for the colorization and lighting and others of the residential area and even office area in our civil engineering construction, which is also an important reflection of environmental philosophy [4].

\subsection{Lack of Automation Philosophy}

In the construction of civil engineering, the lack of automation philosophy will lead to an increase of large labor costs. We should introduce the automation, otherwise the labor cost will continuously rise [5]. At present, with the gradual disappearance of the demographic dividend, the migrant workers who come to cities from villages to engage in simple manual labor are gradually reducing, and the labor costs is continuously increasing. According to the statistics, from 1990 to 2000, the wage of migrant workers in China's urban areas basically keep balance, without change in the ten years; and from 2000 to 2010, the average wage of Chinese migrant workers has quadrupled or more for the ten years, that is, currently the low-end labor is continuously in a urgent demand and the labor cost is increased largely.

The lack of automation philosophy, will lead to an increase of labor cost and also cause a decrease of project quality. As mentioned above, the front-line workers in the construction of civil engineering, are low-end labors from rural areas or small towns, who have no much knowledge of architectural construction and no good comprehension of the construction concept of the designer, and they only have average execution and have no appropriate professional and technical skills for the jobs that they carry out, so the quality of the work done by these workers should be improved. Currently there are frequent problems in quality of urban engineering construction in China, which is directly related with the low quality of overall workers. The use of automated tools for professional operation in place of workers will reduce labor costs and will get a good guarantee of quality.

\section{Several Effective Means to Solve the Current Troubles}

\subsection{Focus on the Development of Deep Foundation Pit Support Technology}

The current urban land gets less and less, both for residential and public use, and high-rise buildings gets more and more popular, while deep foundation pit support technology is mainly used for these high-rise buildings in current urban construction. With the continued development of social technology and the incessant progress of 
our economy and society, high-rise buildings have become normal in the urban construction. For high-rise buildings, there are strict anti-seismic performance criterions [6]. Concretely, we should make application and innovation of pile supporting system in the systematical project construction. The project construction is made under different geological conditions, so we should make accurate analysis of the geological conditions of the construction site during the actual construction. For those loose soil foundation, we must use the prestressed pile technology and cast-in-place pile technology to make the foundation deep-set at maximum before the construction of the ground facilities, to avoid the unstable groundwork. If the groundwater level is exceptional, and for this geological condition, we must use casing water flushing and anchoring process to isolate groundwater, reducing the impact of groundwater on the building quality. The two cases mentioned above are common in the construction, and for the solution of a single problem of these, the application of civil engineering construction is relatively simple and straightforward. However, because of the complexity of the geography and the history in China, there are often multiple difficulties in many conditions of civil engineering construction, and for this more complex geographical conditions, we can use the civil engineering construction process to make reconstruction of the overall geological conditions that is not conducive to the construction and to make it meet the needs of high-rise buildings construction.

For example, Sichuan, Yunnan and Guizhou in China are earthquake-prone areas, and also densely populated areas of China, especially the Sichuan Basin. If the construction of high-rise building is made in the area of high seismic risk, the design and construction technology of civil engineering will face a baptism. For this situation, we can consider the combination method of temporary pile reinforcement technology, permanent technical guidance pile technology and underground wall supporting technology, which can meet the need for bearing and supporting and also prevent seismic disaster, to ensure the residents' safety at maximum in an earthquake.

\subsection{Combine the Construction Technology Development of Civil Engineering and the Environmental Protection}

With more and more frequent extreme weather and more and more frequent environmental problems, we have to concern about the environmental problems in the construction of civil engineering. In practice, the construction technology of civil engineering should be developed in coordination with the environmental protection. As an important way of human to change the nature, we will inevitably cause harm to the environment in the construction of civil engineering, and in future technological development, we should make the construction technology of civil engineering in adaptation and in coordination with the environmental development [7].

Concretely, in the construction of civil engineering, we must focus on the effective planning of environmental protection, and in the use and development and design of building materials, we must pay attention to the combination with environmental protection, to maximize the harmonious development between human and nature. For the construction waste and garbage, we must carry out free-pollution disposal. Solid waste will be inevitably produced in the construction of civil engineering, and these solid wastes mainly including cement, brick, stone and tile brokens, are non-degradable, and will take up a lot of land for their piles, so we must adopt scientific and technological method to make harmless treatment in the construction of civil engineering. First, we can use large machinery to crush and process these solid waste for recycling; second, we can use new technologies and new tools in the construction to minimize the generation of waste; Third, we can establish and improve the matching system, set up specialized plants, use special process for recycling of the litter and waste generated from the industrial buildings, for example, we can crush the brick, stone, tile brokens and then use them to produce new materials, which can save labor costs and minimize the pollution of construction waste for the environment.

\subsection{Introduce the Automated Machinery and Liberate the Labor Force}

From the current situation, the reduction of China's young labor force in a short term is a inevitable trend. The increase of labor costs in China is also an inevitable trend after the demographic dividend is being gradually consumed. In order to reduce labor costs, improve construction efficiency and enhance the quality of the projects, we currently must appropriately introduce the automated machinery and liberate the labor force.

In the specific operation, we first should introduce the concept of assembly line to make the working methods

related to the assembly line involved in the construction of civil engineering. Currently, the first-line work of civil engineering construction must be done by manpower, for example, feeding and bricks laying needs large 
labor and high technologies and quality, so the construction is often in short of labor. Especially in the construction of high-rise building, spider-men may have risk of fall from a height, and once such an incident occurs, it will very likely affect the entire progress of the project, so the construction parties can consider the cooperation with the technology companies and introduce the assembly lines of practical value for those work that has certain risk and needs large labor. At the same time, we should introduce the concept of standardized construction. In the past, the tools used at the construction sites are mostly extensive, and the large machinery such as forklifts and excavators are mostly operated manually, which make the construction effected largely by subjectivity and the quality of work can not be guaranteed fully. Therefore, we should focus on the implementation of technology and determine the construction standards to ensure the quality of the project at maximum [8].

\section{Conclusion}

As the economy entered a new normal, China's real estate industry is facing an unprecedented reshuffle, and in this period, engineering construction companies should focus on the introduction of new technology, the innovation of project and the building of brands during the construction of civil engineering, further to take initiative in the market competition. For the technological innovation of civil engineering construction, we should pay attention to reduction of current low-end labor, prevention of the conflict between human and nature, and prevention of coarse engineering construction, and use modern technology and means to resolve the problems.

\section{References}

[1] Wu, L., Shen, J.Q., Li, J., et al. (2012) The Construction Technology and Innovation of Civil Engineering. Information of Science and Technology, No. 8, 12-13.

[2] Yao, B. (2013) On Information Construction of Civil Engineering. Civil Engineering Journal, No. 9, 45-46.

[3] Xie, Y.Q. (2012) Discussion and Analysis on Application and Development of Prestressed Technology of Civil Engineering. Economic Yearbook of Chinese Entrepreneur in the World • Economics \& Technology and Finance, No. 1, $13-15$.

[4] Guo, Z.X. (2014) On the Innovation and Development of Construction Technology of Civil Engineering. Jiangxi Building Materials, No. 4, 78-79.

[5] Xu, Q. (2014) The Innovation of Engineering Construction Technology. China Engineering and Architecture, No. 5, 62-63.

[6] Li, G.J. (2014) Analysis on Civil Engineering Construction Technology and Its Development. Universal Cultural Geography, No. 8, 46.

[7] Chen, Z. (2014) On the Innovation and Development of Civil Engineering Construction Technology. China Homes (Published in the Last Ten Days), No. 10, 157-158.

[8] Huang, S.W. and Chen, J. (2015) Study on the Innovation and Development of Civil Engineering Construction Technology. No. 1, 62-63. 